\title{
Mechanisms of Urethral Continence and Their Clinical Application
}

\author{
Edward J. McGuire \\ Section of Urology, Department of Surgery, University of Michigan Medical Center, Ann Arbor, Michigan 48109, USA
}

\begin{abstract}
Summary. Controversy about the basic nature of urethral function does not preclude accurate clinical assessment of disorders of function. While the precise method of treatment of urethral continence dysfunction varies from institution to institution, the basic techniques are quite similar. It is the application of a treatment method to a particular case which causes difficulty. It is important, therefore, to have some understanding of the functional elements in the urethral continence mechanism to be able to determine which element does not function. Most cases of intractable incontinence are associated with poor function of the involuntary part of the sphincter. In general, peak urethral closing pressures are unrelated to continence function unless there is no pressure at all.
\end{abstract}

Urethral sphincteric function remains for most urologists something of a mystery. This is particularly apparent with respect to urinary continence after prostatectomy, which few profess to understand; but equal confusion exists with regard to the diagnosis and treatment of poor urethral function and resultant incontinence, as well as the diagnosis and treatment of urethral obstruction resulting from persistent internal sphincter closure in the face of detrusor contractility.

\section{History}

Arguments about the nature of internal sphincter function or dysfunction have been prevalent for at least a hundred years.

In the late 1800s and early 1900s Elliott [1] and von Zeissl [2] demonstrated that hypogastric nerve stimulation evoked urethral "contraction" and pelvic nerve stimulation urethral "relaxation". The basic credit for the concept of a reciprocal relationship between a sympathetically driven smooth sphincter, and a parasympathetically driven bladder belongs to Elliott [1]. Barrington [3] in 1914 confirmed these observations. Langworthy [4], however, denied the assertions of von Zeissl, Elliott, and Barrington, and expressed the idea that opening of the vesical neck was a passive phenomenon related to detrusor contractility. In a pattern that was to be repeated by others, Langworthy cited the anatomical studies of Wesson [5] to confirm his hypothesis. The Langworthy [4] and Wesson [5] viewpoint has until recently prevailed throughout urology, with some notable exceptions.

\section{The Smooth Sphincter as a Passive Organ of Continence and an Active Participant in Voiding}

Woodburne [6] in 1961 summarized the available anatomical and physiologic data in a landmark paper. It was Woodburne's finding that the urethral smooth and detrusor smooth musculature were a continuum. Thus, with a parasympathetically mediated detrusor contraction, the urethra also contracted and pulled itself open. While this appeared to explain the observation that the internal meatus opened with a detrusor contraction, it did not explain closure of the urethra with the bladder at rest. This was partly attributed to a rich plexus of elastic tissue fibers, which were circular in orientation, and partly to the influence of skeletal muscular fibers which constituted the external sphincter. The totally "relaxed" internal sphincter closed itself precisely because it was relaxed. The skeletal muscular elements were shown to both elevate the bladder and lengthen the urethra so that, by Laplace's law, urethral resistance was increased. This provided an antistress mechanism.

Most of Woodburne's basic assumptions were accepted, but even those who accepted them often made minor to major adjustments. Hutch [7] described the deep trigonal musculature, and the inner muscular circle of Uhlenhut, which radiated from it, as forming a urethral enclosure at the bladder neck which, because of the arrangement of the fibers and bundles, resulted in continence. Hutch and many others noted that despite the "absence of a true circular sphincter at the bladder neck," urine was securely held there radiographically. Hutch thought that when micturition began, loss of skeletal sphincter activity occurred, with rupture of the normal flat bladder base plate. Helped 
by the urinary bolus, the urethra opened and stayed open. The detrusor aided that process by pulling on the bladder neck and opening it.

Tanagho [8] reported a series of experiments which began in the late 1960s which, along with the studies of Hutch and Woodburne, had a great influence on present day concepts. Tanagho reported that a fall in urethral closing pressure preceeded normal micturition, and occurred before the change in detrusor pressure. He noted that curare administration led to a $50 \%$ drop in resting urethral closing pressure, which drop occurred in the mid-urethral area. In addition to the mid-urethral fall in pressure, however, prior to the onset of a detrusor contraction, Tanagho noted a fall in urethral closing pressure in the area closed primarily by smooth musculature. This also occurred before a change in intravesical pressure. A similar fall in urethral closing pressure could be induced in the mid-urethra by curarization, and in the more proximal urethra by the administration of atropine. Tanagho stated that, since anatomical studies had clearly demonstrated that the "urethral (smooth muscle could) not (further) relax", the occurrence of a pressure drop in the urethra before an increase in pressure in the bladder indicated that the bladder was not pulling the urethra open. It opened, according to Tanagho, because of the relaxation of the skeletal muscle, which caused it to sag, opening and breaking the base plate which deranged the normal anatomical arrangement of the smooth muscular bundles at the bladder neck. Tanagho also stated that the urethra received its innervation, with the bladder, from the pelvic parasympathetic nerves. As evidence for this he noted that cholinergic agents increased urethral closing pressure, as did pelvic nerve stimulation. Moreover, atropine reduced urethral closing pressure, exerted by smooth musculature.

In another paper, Tanagho presented a body of careful work on urethral closing pressure profiles and the effects of neural stimulation and drugs on urethral pressure $[9,10]$. Epinephrine and norepinephrine were found to increase urethral closing pressure, but these effects were blocked by phenoxybenzamine, which led Tanagho to conclude that the effects were vascular rather than on urethral smooth musculature. Similarly he concluded that, since angiotensin also raised urethral closing pressure, but acted only on vascular tissue, the issue was settled.

These results were somewhat at variance with the ideas of Woodburne since previously the relaxed urethra, unstimulated, was thought to be closed against the bladder simply because it relaxed. Tanagho's data seemed to show that urethral closure was active and parasympathetically mediated. While these results were at odds with the original theory, they did not show any sympathetic influence on the process. If there was any influence of sympathetic activity on urethral function, it was exerted only on the vascular plexus.
While Tanagho's data was generally accepted, the original ideas, Woodburne's and Wesson's, were not abandoned. John Wear [11] asked a reasonable question in a chapter on the neurogenic bladder: "How can relaxation result in an increase in urethral closing pressure?" The question was rhetorical but I find it an extremely perceptive question, and very difficult to answer. Dr. Wear explained the phenomenon largely on the basis of Woodburne's original paper, which had been corroborated by Lapides and co-workers. Lapides [12], however, also showed that the skeletal sphincter was unnecessary for continence. If not, and the data are perfectly valid, how could skeletal sphincteric relaxation also cause the fall in urethral closing pressure noted by Tanagho. Lapides' studies were done in dogs, but others studied man. Brindley and co-workers, in a particularly fascinating study showed, at least in Professor Brindley, that paralysis of the skeletal sphincter did not result in incontinence despite a measured elevation in intra-abdominal pressure of $110 \mathrm{~mm}$ of mercury [13].

Despite considerable evidence, morphologic and physiologic, indicating that smooth sphincter activity was at least influenced in some way by sympathetic neural input, Abrams in 1982 [14], citing the work of Gosling [15], indicated that both the skeletal and smooth urethral sphincter were parasympathetically innervated. That is farther than anybody else has been willing to go in the past.

\section{Critique}

Some critique of this interrelated set of concepts is in order, but it should be noted that I do not think that the observations made by any of these workers are faulty. Indeed, I am amazed at the basic similarity of the data - only the interpretations differ. If one can object to one facet of these studies, it is the tendency to ascribe to anatomical detail direct functional significance. The fact is that an anatomical feature does not by itself mean any more than that. The anatomist is free to draw his own conclusions, but they are speculative, and not functional data.

\section{Opening of the Smooth Sphincter}

There is no question that the internal sphincter opens with detrusor activity. It does so in response to pelvic (parasympathetic) neural stimulation, even if the bladder is removed - which makes it difficult to accept that the detrusor pulls it open. Gosling found the musculature of the bladder and urethra to be distinct, and functionally, urethral and bladder smooth musculature do behave in a reciprocal manner to various drugs, including bethanechol chloride, and alpha-stimulating agents [15].

Influence of Elastic Tissue on Urethral Closure. Elastic tissue fibers are certainly present in the bladder and 


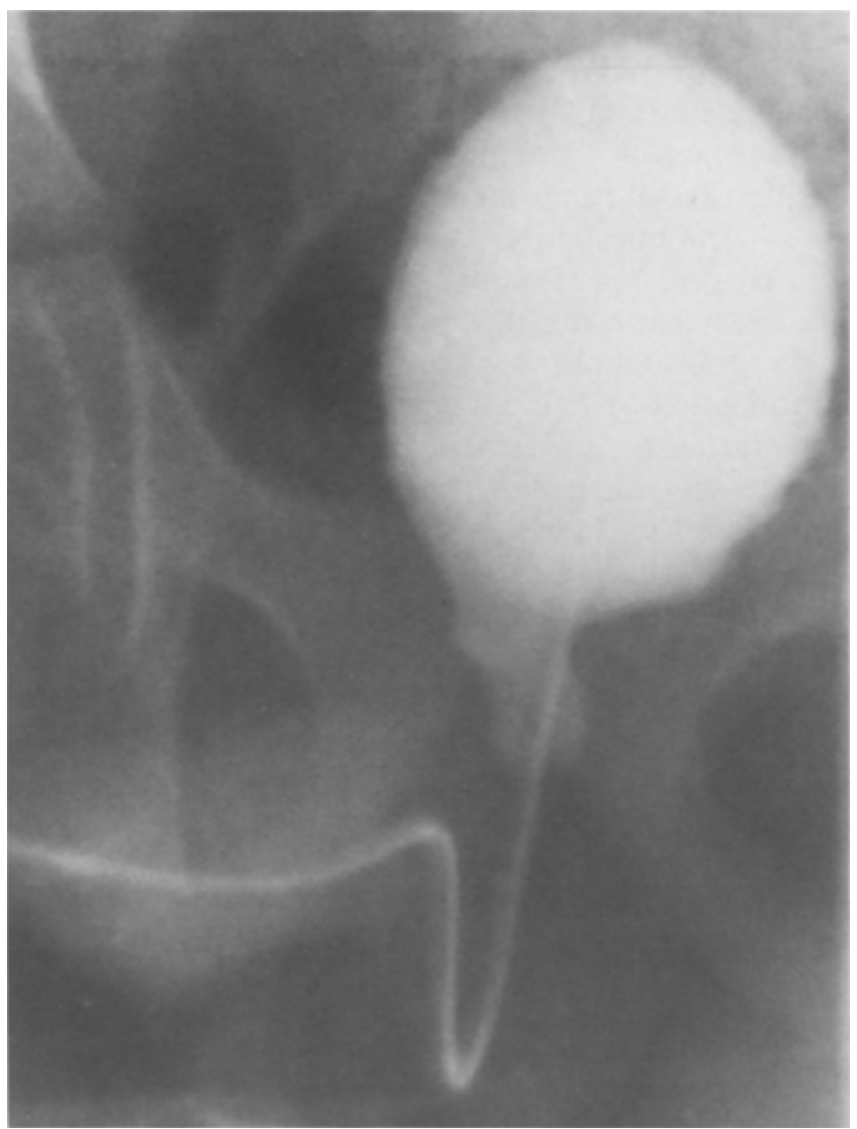

Fig. 1. Myelodysplastic child, 8 years old, with a totally nonfunctional proximal urethra from the bladder outlet to the "membraneous urethra"; peak urethral closing pressure measured $43 \mathrm{~cm} /$ $\mathrm{H}_{2} \mathrm{O}$ in an $0.5 \mathrm{~cm}$ segment between the open proximal urethra and bulbous urethra

urethra, but total loss of urethral smooth muscular closing function can be shown to follow neural injury to the peripheral sympathetic nerves, or a central sympathetic deficit (Fig. 1). These neural lesions would certainly have no effect on tissue elasticity or elastic fibers. Neither would they influence a sphincter which depended on total relaxation to preserve continence.

Laplace's Law. The application of Laplace's law is an interesting idea, which probably explains some aspects of urethral behavior, provided there is some intrinsic closing function. Within the limits of clinical possibility there is little reason to suppose that, if we made a really long urethra with no intrinsic muscular activity, it would function. Postprostatectomy incontinence is incontinence, despite a very long male urethra distal to the nonfunctional urethral sphincter. It remains to be seen whether a 3-foot, or a 30-foot, urethra would be better than the normally closed $1-\mathrm{cm}$ urethra in females after vulvectomy, or males after extensive posterior urethroplasty.

Parasympathetic Innervation of the Urethra. Whether the urethra is parasympathetically and not sympathetically innervated must be proven by something other than the demonstration that angiotensin increases urethral closing pressure. Angiotensin certainly does, and it does it in a muscle bath as well as in vivo. Since it does so, it cannot be considered a pure vascular stimulator. It is difficult to imagine that parasympathetic discharge, which induces bladder contraction, results in an increase in urethral closing pressure in normal circumstances. This would be contrary to the ideas of Woodburne, Wear, Lapides, Wesson and Elliot, who visualized a detrusor contraction causing a decrease in urethral closing pressure. It is not clear to me from Tanagho's writing how he resolves this problem. He clearly shows that a fall in urethral closing pressure, exerted by smooth musculature, preceeds detrusor contractility by a few seconds. The explanation that the fall in smooth muscular-derived urethral closing pressure is the result of skeletal sphincter relaxation is not tenable, since total absence of skeletal sphincteric activity does not diminish urethral closing pressure exerted by smooth muscle, nor influence continence.

\section{The Theory of Dual Innervation of the Lower Urinary Tract and Its Clinical Correlatives}

Histochemical studies in the mid-1960s by Hamberger and Norberg [16] and Elbadawi and Schenk [17] demonstrated that adrenergic neurons and terminals were present in the bladder and urethral smooth musculature.

Gjone [18] showed an influence of sympathetic neural activity on bladder motility and tone, as did Edvardson [19]. The influence of sympathetic neural stimulation on urethral smooth musculature was described in a series of experiments by Kleeman in 1970 [20], which complimented the early work of Learmonth [21]. It was known from scattered reports in the literature that alphaadrenergic blocking agents could induce retrograde ejaculation in males and stress incontinence in females, and that alphaadrenergic agents could precipitate urinary retention in males with prostatism, and the same agents were occasionally useful in enuresis. Raz and Caine in 1972 [22] published a report of the effect of alphaadrenergic agents on urethral smooth muscular activity in females. These observations were quite similar to those made by Learmonth in 1931 regarding sympathetic activity and urethral sphincter function [21]. Nergardth and Boreus studied the role of adrenergic neural receptors and their interaction with cholinergic impulses in the bladder outlet region in the cat [23], as did Raezer and coworkers on the dog in 1973 [24]. DeGroat and Saum showed that sympathetic neural activity inhibited vesical responses to filling and inhibited parasympathetic transmission across pelvic ganglia $[25,26]$. These and other efforts together formed a nucleus of data which strongly indicated that sympathetic neural activity emanating from the thoraco- 
lumbar outflow was involved in bladder and urethral sphincter function by an action on adrenergic receptors, and that adrenergic receptors could in turn be influenced by cholinergic discharge. Kleeman treated patients with reserpine successfully in cases of urinary retention [20]. While most of these studies were experimental, Donker and co-workers showed that the human urethral continence mechanism was similar to the experimental animal in response to alpha-adrenergic blocking and stimulating agents [27].

Brindley and co-workers [13], Drahn and Morales [28], Nemoy and Govan [29], and Calapinto and McCallum [30] demonstrated that external sphincter activity was unnecessary for urinary continence. This was true after prostatectomy, of after repair of a membranous urethral stricture, which destroyed the sphincter. This information suggested that the smooth sphincter mechanism alone was sufficient for continence and that the length required was relatively short, just as Lapides had shown in the dog [12].

Krane and Olsson in 1973 reported their successful experience with phenoxybenzamine, an alpha-adrenergic blocking drug, in the treatment of voiding dysfunction [31]. Although the data was uncontrolled and therapy largely empirical, its rationale was based on the work of Kleeman and the others noted above. Awad and Downie in 1976 published their observations that $60 \%$ of the continence function of the urethra could be attributed to sympathetically driven urethral smooth musculature [32].

In 1975, 1976, and 1977 McGuire, Caine and coworkers reported successful treatment of autonomic dysreflexia associated with internal sphincter dyssynergia, and $\mathrm{BPH}$ with phenoxybenzamine $[33,34,35,36]$. In 1975 McGuire reported that total absence of urethral closing pressure in the smooth sphincter zone could follow abdominal perineal resection for carcinoma of the rectum [37]. Later Woodside and McGuire noted that suprasacral spinal cord injury could be associated with total loss of urethral smooth muscular closing pressure despite a functioning sacral spinal cord [38]. These findings indicated that closure of the urethral smooth musculature was not passive, but active, and required neural input which did not appear to be parasympathetic in nature. Indeed, the neural element in urethral closure appeared to be sympathetic, mediated via an influence on alpha-receptors present in urethral smooth musculature [39]. In a series of experiments in cats, McGuire and Herlihy showed that the intra-abdominal position of the urethral smooth sphincter, provided smooth muscular closure was normal, was an important factor in continence [40]. Changes in intra-abdominal pressure were transmitted equally to bladder and urethra with no net change in urethral closing pressure. Skeletal sphincteric activity was found unnecessary for continence. They further showed that, with detrusor reflex activity elicited by bladder filling, urethral smooth musculature relaxed [41]. Stimulation of the distal stump of the severed $S_{2}$ root resulted in a bladder contraction and a loss of urethral smooth sphincteric pressure. The loss in urethral closing pressure occurred even if the bladder was empty, surgically removed, or the urethral pressure greatly augmented with an alpha-stimulating agent. These findings indicated that the mechanism of urethral opening with detrusor activity was peripheral and not dependent on supression of central sympathetic tonus. The response occurred as a result of cholinergic discharge in the pelvic nerve and preceeded a rise in detrusor pressure precisely as originally described by Tanagho.

\section{Assessment of Urethral Sphincter Function}

Urethral closing pressure profiles have been used to assess urethral sphincteric function. There are a number of modifications of the original technique in use and investigators have attempted to establish that one or the other method was superior [42, 43]. Urethral closing pressure profiles have, in some instances, been fitted to populations. where the underlying diagnosis was already known. Women with "stress incontinence" established clinically were compared with women "without stress incontinence", and were found to have lower peak profile pressures. This does not establish that urethral closing pressure profilometry is an exclusive diagnostic criterion of "stress incontinence". Considerable overlap in urethral closing pressure profile values occur between patients with demonstrable stress urinary incontinence by fluoroscopy, and women with no demonstrable stress urinary incontinence by fluoroscopy [44]. Women with perfectly normal urethral closing pressure profiles can be incontinent, and women with very low pressure profile values can be continent. Of those myelodysplastic children who are incontinent, $86 \%$ demonstrate an open nonfunctional internal sphincter mechanism and preservation of urethral closing pressure in the area associated with external sphincter activity (Fig. 2) [45]. These patients frequently demonstrate peak urethral closing pressure values which are normal or close to normal. Nevertheless, such patients are incontinent. On the other hand, patients subjected to deliberate sacral denervation to control uninhibited detrusor activity demonstrate peak urethral closing pressure values which are much lower than normal as a result of denervation of the skeletal sphincter, and yet these patients can be shown to have a stress competent urethra [39].

Patients with postprostatectomy incontinence typically preserve the ability to volitionally interrupt the dribbling, incontinent stream for short periods of time. In such patients, peak urethral closing pressure profile values are often normal [46] despite the incontinence. On the other hand, women with almost no urethral sphincter function measurable by urethral closing pres- 


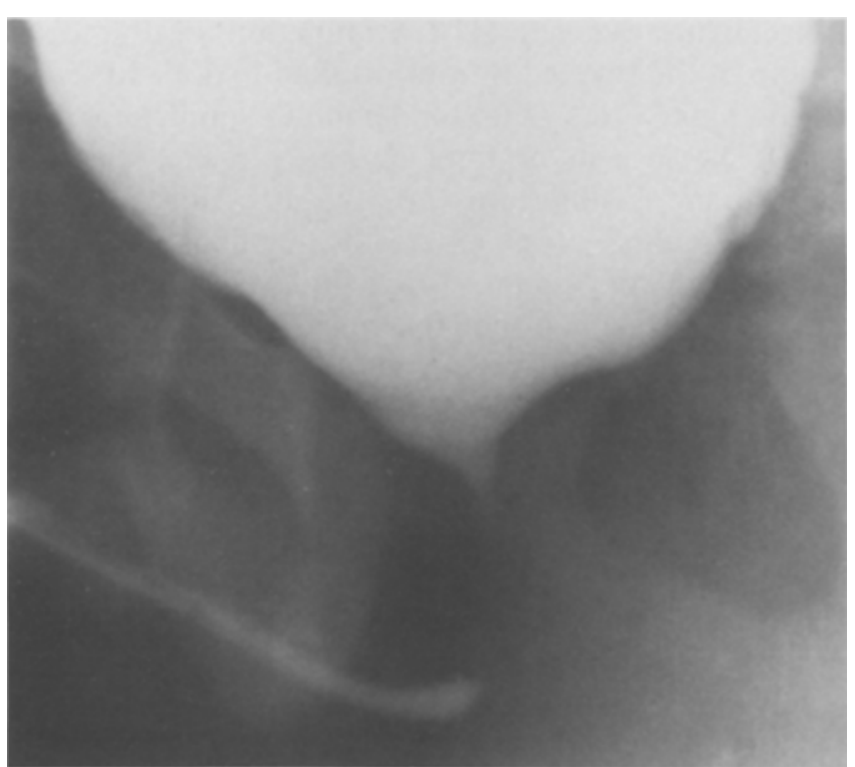

Fig. 2. Myelodysplastic male, 10 years old, with day and nighttime incontinence, stress incontinence, and an open bladder outlet, but radiographic and manometric closure of a $2-\mathrm{cm}$ urethral segment Peak urethral closing pressure was $48 \mathrm{~cm} / \mathrm{H}_{2} \mathrm{O}$

sure profilometry can be made perfectly continent by an increase in urethral closing pressure in the proximal urethra of $6-10 \mathrm{~cm}$ of water, effected by a pubovaginal sling. While these clinical data are not allencompassing, nor do they explain the entire phenomenon of urethral closing pressure profilometry and its relationship to continence, they clearly demonstrate that peak profile values are of little value in an individual case in the assessment of continence function. Indeed, the combination of measurement of urethral closing pressure with fluoroscopy, which permits very precise determination of a urinary leak across the sphincter mechanism, demonstrates that the most important factor in continence is the closing pressure exerted in the proximal or intra-abdominal position of the urethra. Closure of this part of the urethra, where it is exposed to intra-abdominal pressure changes, is more effective then closure of the urethra in the high pressure zone. In this respect, the external sphincter occupies a junctional position at the boundary of the abdominal cavity. Passive transmission of intra-abdominal pressure to this area is less efficient than in the area above it toward the bladder neck. Active compression of the urethra by skeletal sphincteric activity certainly occurs with an increase in intra-abdominal pressure. However, it has been shown that reflex contraction of the external sphincter is unnecessary for a perfectly stress competent urethra, and normal reflex contractility of the external sphincter, in the absence of normal internal sphincter function, is insufficient for continence.

Precise definition of urethral continence function requires urethral closing pressure profilometry, as well as a knowledge of the anatomical point from which urethral closing pressures are being recorded. Assessment of urethral sphincteric function should be done in the upright position. It is true that patients who are incontinent as a result of total loss of urethral sphincter function can be evaluated in the supine position, or even upside down, but in the general population with marginal continence function the upright position, being that position which typically elicits the syndrome of incontinence, is a required feature of the assessment. Radiographically and manometrically the normal urethral closing mechanism begins precisely at the anatomical bladder neck. Pressures in this area in males ascend relatively steeply, and in females less steeply. As the profile catheter continues down the urethra, pressures rise in males to prostatic plateau pressure, which is maintained until the external sphincter region is reached, at which time peak urethral closing pressures are measured until the aperture of the profile catheter reaches a point just distal to the mid-external sphincteric level, at which time pressures drop. The pressure drops in this area because the perfusate finds it as easy to go toward the external meatus as it does to the internal meatus. The artifactual sharp dropoff in pressure occurs proximal to the end of the high pressure sphincteric zone. In normal females, the length of urethra which manifests a pressure higher than intravesical pressure is approximately $2.2 \mathrm{~cm}$. In males, the functional urethral length varies from $3-5 \mathrm{~cm}$, and in some cases of prostatic hypertrophy, it may reach $6-8 \mathrm{~cm}$.

The external sphincter area in females, where both smooth and skeletal muscle elements contribute to urethral closing pressure, is shorter than in males and peak pressures are lower. During bladder filling in the absence of a bladder contraction, urine is held at the bladder neck. After prostatectomy, continence is rarely at the bladder neck and occurs some distance down the prostatic urethra. In patients with preservation of continence after prostatectomy, the continence line begins in the area of the verumontanum. In patients incontinent after prostatectomy the level of continence is distal to the verumontanum, toward the area of peak urethral closing pressure, or that area most closely associated wih skeletal sphincter activity. After a really enthusiastic prostatectomy there may be no continence line at all, but that situation is relatively unusual. In general, the lack of effective closure is detectable between the verumontanum and the peak urethral closing pressure zone, a distance of about $1 \mathrm{~cm}$. Manometrically and fluoroscopically, the urethra from the verumontanum to the external sphincter is incompetent. In most cases of postprostatectomy incontinence, radiographically visible leakage of urine across the crucial area of urethra is eccentric and prejudiced more to one side than the other.

With respect to the simultaneous measurement of bladder and urethral pressures in the assessment of urethral continence function, it is my impression gather- 

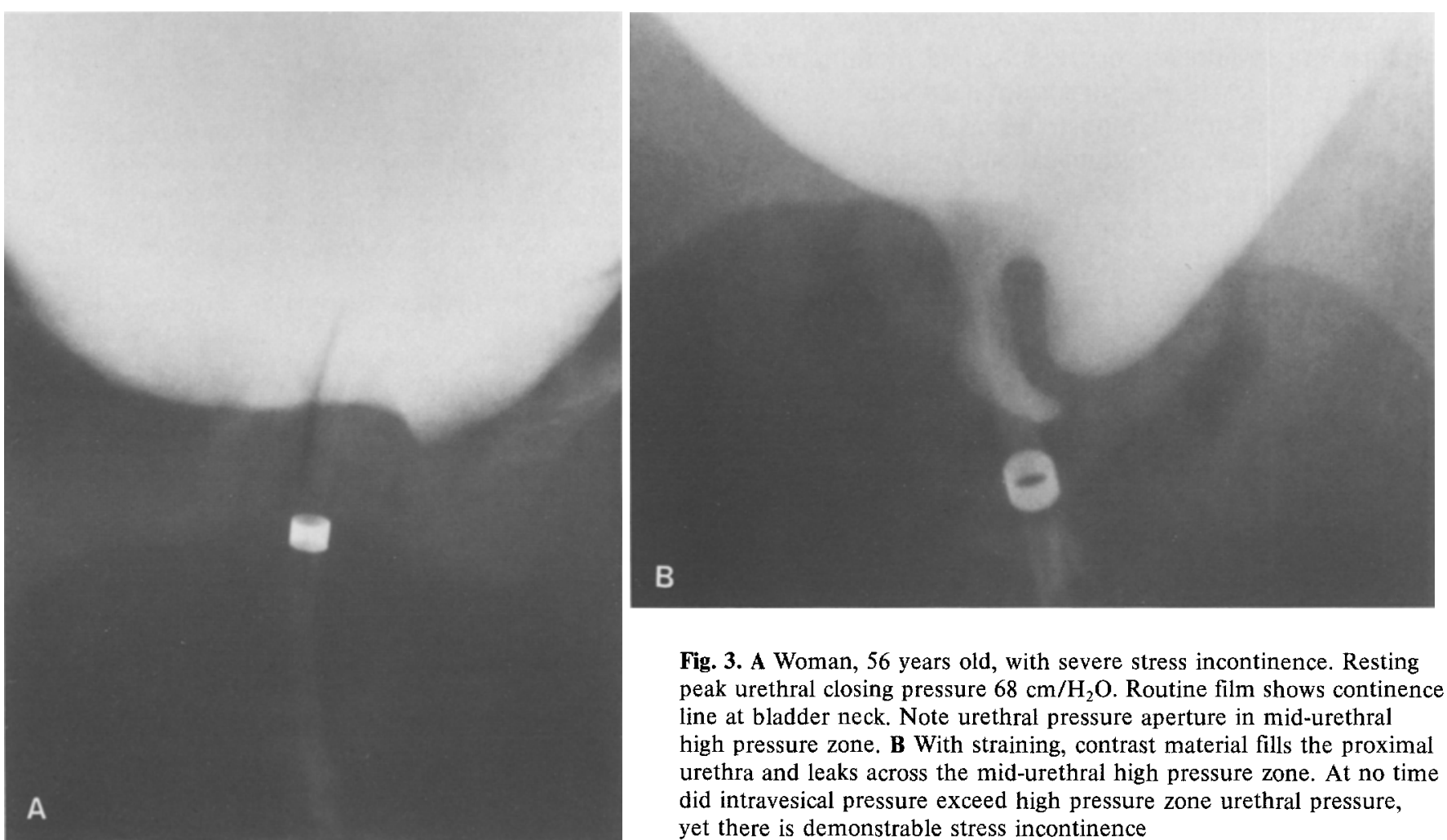

Fig. 3. A Woman, 56 years old, with severe stress incontinence. Resting peak urethral closing pressure $68 \mathrm{~cm} / \mathrm{H}_{2} \mathrm{O}$. Routine film shows continence line at bladder neck. Note urethral pressure aperture in mid-urethral high pressure zone. B With straining, contrast material fills the proximal urethra and leaks across the mid-urethral high pressure zone. At no time did intravesical pressure exceed high pressure zone urethral pressure, yet there is demonstrable stress incontinence

ed from 12 years of such investigations, complimented by fluoroscopy, that instantaneous pressures recorded from the compressive zone of the urethra, i.e. the external sphincter, are not strictly equatable with continence function. We have, from time to time, made the assumption that measured intraurethral pressure by the profile technique in every circumstance is equatable with continence function. Simply stated, that means that a pressure of $80 \mathrm{~cm} \mathrm{H}_{2} \mathrm{O}$ recorded in the external sphincter area with a cough, and a simultaneous pressure of $75 \mathrm{~cm} \mathrm{H} \mathrm{H}_{2} \mathrm{O}$ recorded in the bladder means that no leakage will occur. In fact, that assumption is faulty. The geometry of the urethra and the geometry of the bladder when full or partially full are so different, and the technique of urethral profilometry so artifactual, that elevated pressures in the area of urethra associated with contraction of the external sphincter are not linearly related to resistance offered to up channel urine (Fig. 3 A, B). That is clearly and unequivocally the case in patients with myelodysplasia with reflex contractility of the external sphincter but an open internal sphincter, in patients with postprostatectomy incontinence, and in many women with stress urinary incontinence.

Active contraction of the external sphincter, which induces a sharp rise in intraurethral pressure greater than the rise in intravesical pressure, is not conclusive proof that that urethra does not leak. In fact, the urethra is quite capable of leaking urine across a sphincter which, by the profile technique, has a pressure in one short area higher than intravesical pressure. Therein lies the danger of pressure only urodynamics, in the assessment of urethral sphincter function. I do not believe that there is a linear relationship in every instance between measured intraurethral closing pressure in a single area of the urethra and continence, if one simply compares that momentary pressure excursion with intravesical pressure.

Continuous monitoring of intravesical pressures was reported by James at the International Continence Society Meeting in Antwerp in 1976 . He was occasionally startled by patients who wet their electric nappy, and at those times that wetting was recorded, intravesical pressure was lower than peak urethral closing pressure. This is not a mysterious condition, nor is it a condition engendered by artifactual recording techniques. In fact, it is a common clinical condition known as stress urinary incontinence. I would not go so far as to say that fluoroscopy is essential in every patient with real or suspected sphincteric insufficiency, but I would challenge the implicit assumption which would have us accept the idea that peak urethral closing pressure measured instantaneously can be compared to bladder pressure, and if that peak urethral closing pressure is higher than bladder pressure, stress incontinence or leakage cannot occur. That simply is not true.

How, then, can one assess urethral sphincteric function in marginal cases or in cases where the examiner is uncertain of the diagnosis? In these cases, some radiographic estimation of urethral closing efficiency combined with manometry is helpful. The internal sphincter 
mechanism from the bladder neck to the area of the mid-urethra in females, or the so-called membranous urethra in males is crucial. Urethral closing pressure profilometry clearly demonstrates at the end of the measured increase in urethral pressure over that of the bladder, an area of peak closure which can be augmented by volitional contraction and decreased by volitional relaxation. It is apparent that none of us can volitionally relax nor contract the smooth sphincter element. The area of the mid-urethra in females and the high pressure zone in males, is an area which is not of particular interest in the assessment of passive continence. It does not matter on a clinical level whether these are slow twitch fibers, fast twitch fibers, or even whether they are sympathetically innervated skeletal muscle. It is the area proximal to the high pressure zone which appears to be important with respect to passive urinary incontinence. Urethral closing pressure profilometry alone without fluoroscopy does not permit the examiner to be certain that the onset of positive urethral closing pressure in fact occurs anatomically at the bladder neck. If it does not, a normally functioning external sphincter in a male is long enough and manifests a high enough pressure so that urethral peak closing pressure profile values are relatively normal, despite the fact that the patient is incontinent. In females, anatomical assessment is even more critical since the length of the urethra proximal to the high pressure zone is short.

The best way to assess urethral sphincteric function is to withdraw a urodynamic catheter perfused with $20 \%$ radiopaque contrast material though the urethra while one simultaneously measures intravesical pressure, watches the process fluoroscopically, and intermittently has the patient increase intraabdominal pressure. Fluoroscopy reliably demonstrates whether or not material from the bladder leaks across the sphincteric mechanism. If that is the case, the profile pressures, if correlated precisely with the anatomical area from which those pressures are recorded, gives the examiner a precise assessment of urethral sphincteric function and allows him to decide which part of the urethral sphincteric mechanism is poorly functional. In addition, the fluoroscopic assessment of urethral function allows the examiner to visualize urethral mobility or the posterior and inferior rotational descent of the urethra with an increase in intra-abdominal pressure which occurs in stress urinary incontinence. Such urethral mobility can be associated with urinary loss, despite a normal urethral closing pressure profile, and, if present, can be repaired by an appropriate operation.

\section{References}

1. Elliot TR (1907) The innervation of the bladder and urethra. J Physiol 25:367
2. Von Ziessl M (1983) Über die Innervation der Blase. Pflügers Arch Physiol 53:560

3. Barrington FJF (1914) The physiology of micturition. Q J Exp Physiol 8:33

4. Langworthy OR, Drew JE, Vest SA (1940) Urethral resistance in relation to vesical activity. $J$ Urol $43: 123$

5. Wesson MB (1920) Anatomical embryological and physiological studies of the trigone and neck of the bladder. J Urol 34:279

6. Woodburne RT (1968) Anatomy of the bladder and bladder outlet. J Urol 100:474

7. Hutch JA (1967) A new theory of the anatomy of the internal urinary sphincter and the physiology of micturition. IV. The urinary sphincteric mechanism. J Urol 97:705

8. Tanagho EA (1971) Interpretation of the physiology in micturition. In: Hinman $F$ (ed) Hydrodynamics of micturition. Thomas, Springfield, Ill, p 18

9. Tanagho EA, Meyers FH, Smith DR (1969) Urethral resistance: its components and implications. 1 . Smooth muscle component. Invest Urol 7:195

10. Tanagho EA, Meyers FH, Smith DR (1969) Urethral resistance: its components and implications. II. Skeletal muscle component. Invest Urol 7:195

11. Wear JB (1973) The neurogenic bladder. In: Karafin L, Kendall AR (eds) Urology. Harper \& Row, New York

12. Lapides J, Sweet RB, Lewis LW (1957) Role of striated muscle in urination. J Urol 77:247

13. Brindley GS, Rushton DN, Craggs MD (1974) The pressure exerted by the external sphincter of the urethra when its motor nerve fibers are stimulated electrically. $\mathrm{Br} J$ Urol 46:453

14. Abrams P (1982) Urodynamic investigations. Monogr Urol 3:3

15. Gosling J (1979) The structure of the bladder and urethra in relation to function. Urol Clin North Am 6:31

16. Hamberger B, Norberg KA (1965) Adrenergic synaptic terminals and nerve cells in the bladder of the cat. Int $\mathbf{J}$ Neuropharmacol $4 \cdot 41$

17. Elbadawi A, Schenk EA (1974) A new theory of the innervation of the bladder musculature. III. Innervation of vesicourethral junction and external urethral sphincter. J Urol 111: 613

18. Gjone R (1965) A dual peripheral and supra-spinal autonomic influence on the urinary bladder. J Oslo City Hosp 15:173

19. Edvardsen P (1968) Nervous control of the urinary bladder in cats. I. The collecting phase. Acta Physiol Scand 72:157

20. Kleeman FJ (1970) The physiology of the internal urinary sphincter. J Urol 104:549

21. Learmonth JR (1931) A contribution to the neurophysiology of the urinary bladder in man. Brain 54, pt 1,2

22. Raz S, Caine $M$ (1972) Adrenergic receptors in the female canine urethra. Invest Urol 9:319

23. Nergardh A, Boreus LO (1973) The functional role of cholinergic receptors in the outlet region of the urinary bladder: an in vitro study in the cat. Acta Pharmacol Toxicol 32:467

24. Raezer DM, Wein AJ, Jacobowitz D, Corriere JN Jr (1973) Autonomic innervation of canine urinary bladder: cholinergic and adrenergic contributions and interaction of sympathetic and parasympathetic systems in bladder function. Urology 2:211

25. DeGroat WC, Saum WR (1976) Synaptic transmission in parasympathetic ganglia in the urinary bladder of the cat. J Physiol 256:137

26. Saum WR, DeGroat WC (1972) Parasympathetic ganglia: activation of an adrenergic inhibitory mechanism by cholinomimetic agents. Science 175:659

27. Donker PJ, Ivanovici F, Nooch EL (1972) Analyses of the urethra pressure profile by means of electromyography and the administration of drugs. Br $\mathbf{J}$ Urol 44:180

28. Drahn HP, Morales PA (1965) The effect of pudendal nerve anesthesia on urinary continence after prostatectomy. J Urol $94: 282$ 
29. Nemoy NJ, Govan DE (1969) Urinary continence in the absence of an intact external sphincter. J Urol 102:200

30. Calapinto V, McCallum RW (1976) Urinary continence after repair of membranous urethral stricture in prostatectomized patients. J Urol 115:392

31. Krane RJ, Olsson CA (1973) Phenoxybenzamine in neurogenic bladder dysfunction. II. Clinical considerations. J Urol 110:653

32. Awad SA, Downie JW (1976) The effect of adrenergic drugs and hypogastric nerve stimulation on the canine urethra: a radiographic and urethral pressure study. Invest Urol 13:298

33. McGuire EJ (1977) Urethral closing pressure after spinal cord injury and its relationship to automatic dysreflexia. Urol Int 32:97

34. Caine M (1975) Some clinical implications of adrenergic receptors in the urinary tract. Arch Surg 110:247

35. McGuire EJ, Wagner F, Weiss RM (1976) Treatment of autonomic dysreflexia with Phenoxybenzamine. J Urol 115:53

36. Caine M, Pfau A, Perlberg S (1976) The use of adrenergic blockers in benign prostatic obstruction. Br J Urol 48:255

37. McGuire EJ (1975) Urodynamic evaluation after abdominal perineal resection or lumbar intervertebral disc herniation. Urology 6:63

38. Woodside JR, McGuire EJ (1979) Urethral hypotonicity follow- ing suprasacral spinal cord injury. J Urol 121:783

39. McGuire EJ, Wagner F (1977) The effects of sacral denervation on bladder and urethral function. Surg Gynecol Obstet 114:343

40. McGuire EJ, Herlihy E (1977) The influence of urethral position on urinary continence. Invest Urol 15:205

41. McGuire EJ, Herlihy E (1978) Bladder and urethral response to isolated sacral motor root stimulation. Invest Urol 16:219

42. Tanagho EA (1979) Membrane and microtransducer catheters: their effectiveness for profilometry of the lower urinary tract. Urol Clin North Am 6:110

43. Tanagho EA, Jonas U (1977) Membrane catheter: effective for recording pressures in the lower urinary tract. Urology 10:173

44. McGuire EJ, Lytton B, Pepe V, Kohorn EI (1976) Stress urinary incontinence. Obstet Gynecol 47:255

45. McGuire EJ, Woodside JR, Bordon TA, Weiss RM (1981) Prognostic value of urodynamic testing in myelodysplasia. J Urol 126:205

46. Leach GE, Raz S (1984) Management of complicated sphincteric incontinence: silicone gel prosthesis. In: Barrett DM, Wein AJ (eds) Controversies in neurourology. Churchill Livingstone, New York, p 377 